\title{
CORRELATION OF DIFFERENT OBSTETRICAL FACTORS WITH HEMOGLOBIN LEVEL IN PREGNANT FEMALES.
}

\footnotetext{
1. FCPS

Assistant Professor Obstetrics and Gynecology College of Medicine Taif University.

2. FCPS, Professor of Anatomy Watim Medical College Rawalpindi

3. FCPS

Assistant Professor Obstetrics and Gynecology

University Medical \& Dental College, Faisalabad.

4. FCPS

Senior Registrar Security Forces Hospital Makkah, KSA

Assistant Professor Medicine UMDC.

5. FCPS

Associate Professor Medicine Aziz Fatima Medical and Dental

6. FCPS

Consultant Nephrologist

King Abdul Aziz Hospital, Taif.
}

Correspondence Address:

Dr. Imran Nazir Ahmad

278-Jinnah Colony, Faisalabad.

Pakistan.

imrannazir40@gmail.com

Article received on:

04/07/2019

Accepted for publication

00/00/2019
Iffat Imran', Nusrat Zareen², Umber Fatima ${ }^{3}$, Imran Nazir ${ }^{4}$, Rizwan Rasul Khan ${ }^{5}$, Muhammad Ajmal Farid ${ }^{6}$

ABSTRACT... Objectives: To assess the correlation of different obstetrical factors with the hemoglobin level in multiparous pregnant females in Taif KSA. Anemia in pregnancy is a multifactorial phenomenon, among which obstetrical factors like parity, previous $\mathrm{H} / \mathrm{O}$ abortions, inter pregnancy interval, mode of delivery etc are frequently associated. Study Design: Observational study. Setting: Outpatient department in King Faisal Hospital (KFH), Taif, Saudi Arabia. Period: $1^{\text {st }}$ June 2018 and 31 ${ }^{\text {st }}$ August 2018. Material \& Methods: Conducted in 200 pregnant women by random sampling technique. Hemoglobin value and all patient's data was noted. All data was fed to SPSS version 23.0 and statistically analyzed using chi square test for qualitative and student's t test for quantitative data. Results: The study was conducted in 200 patients that showed that there was no statistically significant association of increasing parity, inter pregnancy interval, mode of delivery (NVD or Cesarean section) \& history of anemia and $\mathrm{PPH}$ in preceding pregnancy with the Hemoglobin level. While history of previous abortion is associated and a risk factor for anemia in pregnancy, 50\% with history of 01 previous abortion had anemia while $100 \%$ of the cases with history of 02 previous abortions had moderate anemia. (Table-II). This association was observed statistically significant with $p$ value of 0.001 . Conclusion: This study concluded that anemia is a predictable as well as preventable entity. Obstetrical factors may be the contributory factors of anemia in pregnancy. Health education awareness programs, regular antenatal visits and iron supplements can be helpful to improve heath of pregnant women.

Key words: Hemoglobin Level, Mild Anemia, Moderate Anemia, Severe Anemia, PPH.

Article Citation: Imran I, Zareen N, Fatima U, Nazir I, Khan R R, Farid A. Correlation of different obstetrical factors with hemoglobin level in pregnant females. Professional Med J 2020; 27(3):625-630. DOI: 10.29309/TPMJ/2020.27.3.3901

\section{INTRODUCTION}

Anemia is a worldwide health issue especially affecting the pregnantwomen and young children. ${ }^{1}$ It is defined by reduced hemoglobin concentration in the blood. ${ }^{2}$ World Health Organization (WHO) recommended anemia values to be followed during pregnancy are: Anemia (hemoglobin level $<11 \mathrm{~g} / \mathrm{dl}$ ), Mild anemia (hemoglobin level 10 $-10.9 \mathrm{~g} / \mathrm{dl}$ ), Moderate anemia (hemoglobin level $7-9.9 \mathrm{~g} / \mathrm{dl}$ ) and Severe anemia (hemoglobin level $<7 \mathrm{~g} / \mathrm{dl}$ ). ${ }^{3}$ Iron deficiency being the commonest cause of anemia during pregnancy. Throughout the world, around half of the pregnant ladies start their pregnancy with extremely low iron reserves (serum ferritin $<30 \mathrm{mg} / \mathrm{l}$ ) and among remainders, a vast majority have inadequate reserves (iron stores of $<500 \mathrm{mg} \&$ serum ferritin $<70 \mathrm{mg} / \mathrm{l}$ ), which cannot fulfil the increased iron needs during pregnancy and result in anemia. ${ }^{3}$ The prenatal anemia is among one of the greatest risk factors for adverse outcome. Mothers with prenatal anemia have more chances of preterm labour, low birth weight infants, infections, postpartum hemorrhage and even maternal mortality. ${ }^{1}$ In fact, anemia during pregnancy is considered as one of the most common indirect obstetric cause of maternal mortalities ${ }^{4}$ similarly, the affected neonates have cognitive and behavioral problems that are sometimes irreversible even after iron replacement. ${ }^{5}$

Anemia during pregnancy is a multifactorial entity. Nutritional factors, chronic illnesses, short birth intervals, bleeding during pregnancy and increasing parity are important obstetrical factors ${ }^{6}$ which affect hemoglobin levels during anemia. 
In Saudi Arabia the large family's concept is highly appreciated and a scanty research is available to date to investigate the association of different obstetrical factors to development of anemia in pregnancy in Saudi population. ${ }^{7,8}$

Therefore, the present study was designed to assess the hemoglobin levels and associated obstetrical risk factors related to it, among pregnant women receiving antenatal care at King Faisal Hospital Taif KSA.

\section{MATERIAL AND METHODS}

An observational study was designed from the period between $1^{\text {st }}$ June 2018 and $31^{\text {st }}$ August 2018 , total of 200 women were recruited from the outpatient department in King Faisal Hospital (KFH), Taif, Saudi Arabia by convenient sampling technique at the time of their booking antenatal visit. The Participants were classified into two groups according to parity: multipara [1-4 births], and grand multipara [5 or more births.

Pregnant women with multiple gestations; chronic medical illnesses such as renal and cardiac diseases and patients suffering from hereditary anemias were excluded from the study. An informed verbal consent was obtained from all participants prior to their participation in the study.

Careful medical and Socio-demographic history was obtained from every patient including detailed information about inter pregnancy interval, $\mathrm{H} / \mathrm{O}$ anemia and mode of delivery during preceding pregnancy as well as previous abortions to know any associated factors that could lead to low iron reserves and development of anemia in understudy pregnancy.

Association of different obstetrical factors including parity, history of abortions, inter pregnancy interval, anemia or $\mathrm{PPH}$ and mode of delivery of preceding pregnancies were assessed against development of anemia in the presenting pregnant women.

Different modalities were further categorized to assess their effects on anemia development in the cases studied. The presenting women were categorized on the basis of their ages as, $<20$, $21-25,26-30,31-35,36-40$ and $<40$ years. Parity was considered in 02 categories, first comprising of Multipara 1-4 women, while second comprising of grand multipara (P 5 or more).

Similarly, women with history of previous abortions were also categorized as women with history of Nil, 01 or 02 abortions respectively.

The inter pregnancy interval in presenting women was recorded and analyzed as $<6$ months between 6-12 months, 1-1.5 Years, 1.5-2 years or $>2$ years.

Association between anemia in pregnancy and mode of delivery in the preceding pregnancy e.g. SVD, or caesarian section was also analyzed.

Presence or absence of anemia or PPH in the preceding pregnancy was also assessed for a possible cause of anemia in the presenting pregnancy.

All data was fed to SPSS version 23.0 and statistically analyzed using chi square test for qualitative and student's t test for quantitative data. Statistical association was analyzed between obstetrical factors like parity, previous abortions, inter pregnancy interval, mode of delivery, history of anemia in preceding pregnancy and anemia in the current pregnancy. A $p$ value of $<0.05$ was considered statistically significant.

\section{RESULTS}

The first recorded $\mathrm{Hb}$ of the presenting women was analyzed against the data retrieved for these women for any association. Although the eldest age group of $>40$ years had more recorded cases of anemia as compared to the youngest girls, the difference was not statistically significant.

Regarding the parity of the presenting women there was no association of increasing parity and the development of anemia or otherwise (Table-I). The number of women with parity 1 to 4 , had more normal $\mathrm{Hb}$ levels $(n=93)$ as compared to grand multipara women $(n=16)$. On the other hand, the number of females in the lesser parity category had lesser tendency to develop anemia either 
mild, moderate or severe $(n=71)$ as compared to grand multipara women $(n=20)$. However, none of these associations were statistically significant.

History of previous abortions had a significant effect on the $\mathrm{Hb}$ values of the cases studied. 54\% of women with no previous history had some level of anemia, $50 \%$ with history of 01 previous abortion had anemia while $100 \%$ of the cases with history of 02 previous abortions had moderate anemia. (Table-II). The association of recorded $\mathrm{Hb}$ value and history of previous abortions was observed to be statistically significant with a $p$ value of 0.001

Whereas the majority of cases (54.5\%) who had inter pregnancy internal of more than 2 years had normal $\mathrm{Hb}$ value range, the data analyzed statistically had no significant association to the recorded $\mathrm{Hb}$ value.

Table-III summarizes other factors analyzed like presence or absence of anemia, or PPH or Mode of delivery in the preceding pregnancy. None of these had any significant association to the recorded $\mathrm{Hb}$ level (Table-IV).

\begin{tabular}{|l|c|c|c|c|c|c|}
\hline \multirow{2}{*}{ Parity } & \multicolumn{4}{|c|}{ HB Level } & \multicolumn{1}{|c|}{$\begin{array}{c}\text { Total } \\
\text { Cases }\end{array}$} \\
\cline { 2 - 7 } & Normal HB & Mild Anemia & Moderate Anemia & Severe Anemia & 164 \\
\hline $1-4$ & 93 & 48 & 21 & 2 & 0.24 \\
\hline 5 or $>$ & 16 & 11 & 9 & 0 & 36 \\
\hline
\end{tabular}

Table-I. Association of maternal parity and recorded $\mathrm{HB}$, using $\mathrm{CHI}$ square test.

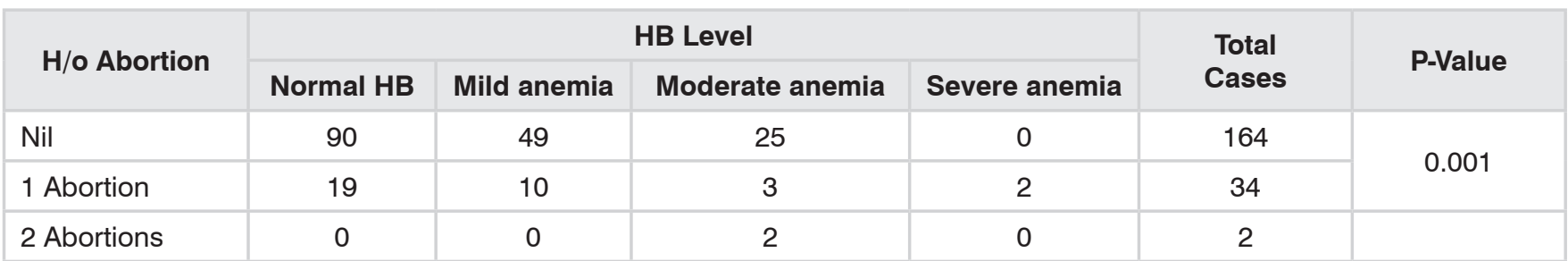

Table-II. Association of H/O Abortion \& recorded HB, using CHI square test.

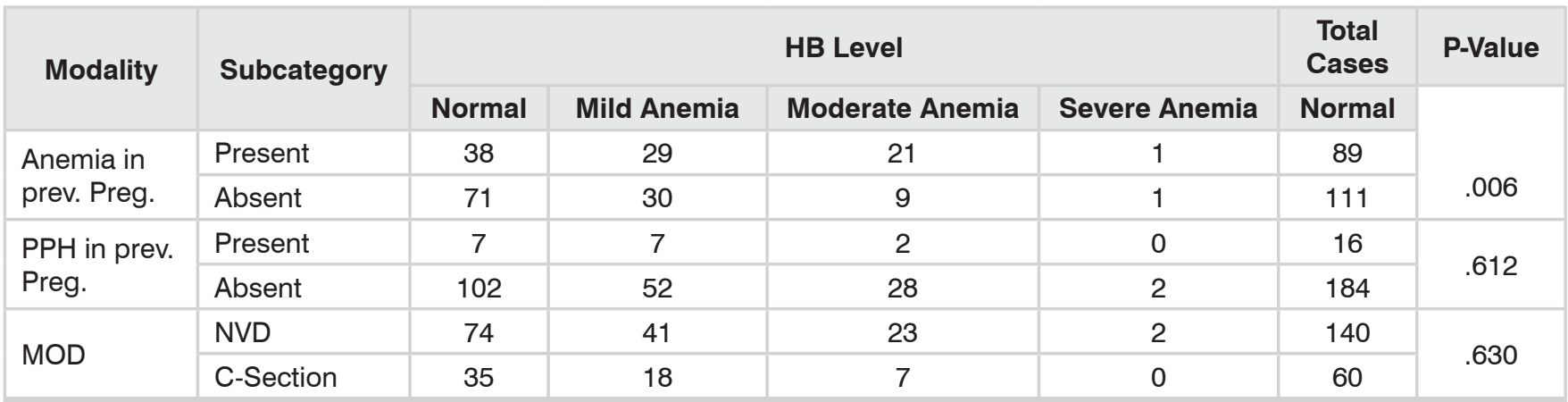

Table-III. Association of interpregnancy interval (IPI) \& recorded HB, using CHI square test.

\begin{tabular}{|c|c|c|c|c|c|c|}
\hline \multirow{2}{*}{ IPI } & \multicolumn{4}{|c|}{ HB Level } & \multirow{2}{*}{$\begin{array}{c}\text { Total } \\
\text { Cases }\end{array}$} & \multirow{2}{*}{ P-Value } \\
\hline & Normal HB & Mild Anemia & Moderate Anemia & Severe anemia & & \\
\hline$<6$ months & 11 & 3 & 3 & 0 & 17 & \multirow{3}{*}{0.86} \\
\hline 1-1.5 yrs. & 15 & 10 & 2 & 0 & 27 & \\
\hline $1.5-2$ yrs. & 17 & 5 & 4 & 0 & 26 & \\
\hline
\end{tabular}

Table-IV. Association of different obstetrical modalities \& recorded HB, using CHI square test. 


\section{DISCUSSION}

Anemia in pregnancy is a common observation. More than half of the pregnant women in the world have hemoglobin levels indicative of anemia. ${ }^{9}$

As anemia is the most frequent maternal complication of pregnancy, its early detection and factors contributing to its development calls for special attention to it. Its early detection and management is vital for proper antenatal care. ${ }^{10}$

Despite is a high prevalence of anemia during anemia with severe consequences on health, social, and economic development, there is no recent evidence on the magnitude of the prenatal anemia. ${ }^{11}$

Anemic pregnant women will be at risk of low physical activity, increased maternal morbidity and mortality, especially those with severe anemia. $^{12}$

The present study was designed assess the hemoglobin levels and associated obstetrical risk factors related to it, among pregnant women receiving antenatal care at King Faisal Hospital Taif, Saudi Arabia. We analyzed the association of obstetrical factors including parity, history of abortions, inter pregnancy interval, anemia or $\mathrm{PPH}$ and mode of delivery of preceding pregnancies to development of anemia in the presenting pregnant women.

In the present study most of the studied obstetric, although related, did not prove to be significantly associated to the presence of anemia in pregnancy.

Regarding the association of age to maternal anemia the elder age group years had more recorded cases of anemia as compared to the younger girls the difference was not statistically significant. These results are corresponding to previous literature where maternal anemia was not associated to the age of the mother. ${ }^{13}$ However in general, studies emphasize that the anemia prevalence rate is specifically higher among women of reproductive age. ${ }^{14}$ However even this association was not statistically manifested in our results.

Despite the non-association of anemia to age observed in our study and previous literature there are a few studies which do report the significant association. One of the studies conducted in Congo report that anemia was also found linked to extremes of reproductive ages, i.e. $<18->35 .{ }^{15}$

The parity of the presenting women revealed a relation to anemia but the association was not statistically significant. The number of females in the lesser parity category had lesser tendency to develop anemia either mild, moderate or severe as compared to grand multipara women. The similar results were also reported in previous studies where anemia seems to be higher among women with parity more than three, but it was not statistically significant. ${ }^{16}$

In some studies, however statistically significant association of anemia and increasing parity was reported. ${ }^{17}$

History of previous abortions had a significant effect on anemia in the present study. Hundred percent of women with previous 02 abortions were recorded to have anemia. Similar association of anemia to miscarriages is reported by scientists, where anemia was also found to significantly linked to previous miscarriages. ${ }^{15}$

Regarding the association of inter pregnancy interval, in our no study no significant association to the recorded $\mathrm{Hb}$ value was recorded. Previous literature however endorses that short interpregnancy intervals (IPIs) have been associated with adverse maternal and infant health outcomes in the literature. ${ }^{18}$

A retrospective cohort study, in 2014-16 specifically reported that Short inter pregnancy interval is an independent risk factor for anaemia. It was thought to be related with maternal depletion theory and the increasing risk of bleeding in pregnancy. ${ }^{19}$

Other factors analyzed like presence or absence of anemia, or PPH or Mode of delivery in the 
preceding pregnancy also did not have any significant association to development of anemia in our study. Considering the prevalence of anemia during pregnancy and non-association to the related obstetrical factors in our study, other factors should be taken into account for prevention, diagnosis and management of the condition.

Taner et al in 2015 have reported the association of maternal anemia to the socio-economic conditions. Low socio-economic conditions have been considered a risk factor for maternal anemia. ${ }^{20}$ While a group of scientists in 2019 have emphasized on health education on family planning and the importance of taking of iron tablet to reduce the prevalence of maternal anemia. $^{21}$

\section{CONCLUSION}

Majority of the obstetric modalities assessed in this study did not prove to be a significant factor affecting the $\mathrm{Hb}$ level of the pregnant females. The small sample size and the unequal number of cases could be a bias in the study.

In our study the only obstetrical factor that was observed to have a significant association with development of anemia was history of previous abortions. Females who had previous history of abortions developed anemia in the current pregnancy. Whereas maternal age, her parity, inter pregnancy interval, mode of delivery and presence of anemia or $\mathrm{PPH}$ in the preceding pregnancy do not have any significant association to her $\mathrm{Hb}$ levels in the present pregnancy. In this regard, a more elaborate study is suggested with proportionate number of cases under each category to better analyze the influence of obstetrical factors on the development of anemia in pregnant females.

\section{Copyright (}

\section{REFERENCES:}

1. Derso T, Abera Z Tariku A. Magnitude and associated factors of anemia among pregnant women in Dera District: A cross-sectional study in northwest Ethiopia. BMC Res Notes. 2017; 10(1):359.
2. Lebso M, Anato A, Loha E. Prevalence of anemia and associated factors among pregnant women in Southern Ethiopia: A community based crosssectional study. PLoS One. 2017 11; 12(12):e0188783.

3. Breymann C. Iron deficiency anemia in pregnancy. Obstet Gynecol. Semin Hematol. 2015; 52(4):339-47.

4. Alemu T, Umeta M. Reproductive and obstetric factors are key predictors of maternal anemia during pregnancy in Ethiopia: evidence from demographic and health survey (2011). Anemia. 2015;2015.

5. Özdemir N. Iron deficiency anemia from diagnosis to treatment in children. Turk Pediatri Ars. 2015 1; 50(1):11-9.

6. Kavle JA, Stoltzfus RJ, Witter F, Tielsch JM, Khalfan SS, Caulfield LE. Association between anaemia during pregnancy and blood loss at and after delivery among women with vaginal births in Pemba Island, Zanzibar, Tanzania. J Health Popul Nutr. 2008; 26(2):232-40.

7. Alzaheb RA, Al-Amer $\mathrm{O}$. The prevalence of iron deficiency anemia and its associated risk factors among a sample of female university students in Tabuk, Saudi Arabia. Clinical Medicine Insights: Women's Health. 2017 Nov 30;10:1179562X17745088.

8. AIQuaiz AM, Gad Mohamed A, Khoja TA, AISharif A, Shaikh SA, Al Mane H, Aldiris A, Kazi A, Hamad D. Prevalence of anemia and associated factors in child bearing age women in Riyadh, Saudi Arabia. Journal of nutrition and metabolism. 2013 Sep 24;2013.

9. Dim CC, Onah HE. The prevalence of anemia among pregnant women at booking in Enugu, South Eastern Nigeria. Med Gen Med. 2007 Jul 11; 9(3):11.

10. Gedefaw L, Ayele A, Asres Y, Mossie A. Anemia and associated factors among pregnant women attending antenatal care clinic in Wolayita Sodo Town, Southern Ethiopia. Ethiop J Health Sci. 2015 Apr; 25(2):155-62.

11. Worku Takele W, Tariku A, Wagnew Shiferaw F, Demsie A, Alemu WG, Zelalem Anlay D. Anemia among women attending antenatal care at the university of gondar comprehensive specialized referral Hospital, Northwest Ethiopia, 2017. Anemia. 2018.

12. Benoist B, McLean E, Cogswell M, Egli I, Wojdyla D. Worldwide prevalence of anemia, WHO Vitamin and Mineral Nutrition Information System, 19932005. Public Health Nutr, Geneva. 2008; 12(4):444-454. 
in pregnancy and its associated factors among primary care clients in Sagamu, Southwest, Nigeria: A facility-based study. J Family Med Prim Care. 2017 Apr-Jun; 6(2):323-329.

14. Saydam BK, Genc RE, Sarac F, Turfan EC. Prevalence of anemia and related factors among women in Turkey. Pak J Med Sci. 2017 Mar-Apr; 33(2):433-438.

15. Tandu-Umba B, Mbangama AM. Association of maternal anemia with other risk factors in occurrence of Great obstetrical syndromes at university clinics, Kinshasa, DR Congo. BMC Pregnancy Childbirth. 2015 Aug 21; 15:183.

16. Suryanarayana $R$, Chandrappa $M$, Santhuram $A N$, Prathima S, Sheela SR. Prospective study on prevalence of anemia of pregnant women and its outcome: A community based study. J Family Med Prim Care. 2017 Oct-Dec; 6(4):739-743.

17. Obse N, Mossie A, Gobena T. Magnitude of anaemia and associated risk factors among pregnant women attending antenatal care in Shalla Woreda, West Arsi Zone, Oromia Region, Ethiopia. Ethiop J Health Sci. 2013; 23:165.

18. Wendt A, Gibbs CM, Peters S, Hogue CJ. Impact of increasing inter-pregnancy interval on maternal and infant health. Paediatr Perinat Epidemiol. 2012 Jul; 26 Suppl 1(0 1):239-58.

19. Riyanto, D. L, Herdian, F. S; Sugiarta, G. Y et al. Short Inter pregnancy Interval as a Risk Factor for Anemia in Pregnancy: A Retrospective Cohort Study in Duren Sawit, Jakarta, 2014-2016. Advanced Science Letters, 2017; 23. 6828-6830.

20. Taner CE, Ekin A, Solmaz U, Gezer C, Çetin B, Keleşoğlu $M$, Erpala MB, Özeren M. Prevalence and risk factors of anemia among pregnant women attending a highvolume tertiary care center for delivery. J Turk Ger Gynecol Assoc. 2015 Nov 2; 16(4):231-6.

21. Ali MM et al. Int J Community Med Public Health. 2019 Mar; 6(3):950-957.

\begin{tabular}{|c|l|l|l|}
\hline \multicolumn{3}{|c|}{ AUTHORSHIP AND CONTRIBUTION DECLARATION } \\
\hline Sr. \# & \multicolumn{1}{|c|}{ Author(s) Full Name } & Contribution to the paper & Author(s) Signature \\
\hline 1 & Iffat Imran & 1st Author & 2nd Author \\
\hline 2 & Nusrat Zareen Bashir & 3rd Author \\
\hline 4 & Umber Fatima & Imran Nazir & 4th Author \\
\hline 5 & Rizwan Rasul Khan & 5th Author \\
\hline 6 & Muhammad Ajmal Farid & 6th Author
\end{tabular}

